\title{
Limited value of procalcitonin, C-reactive protein, white blood cell, and neutrophil in detecting bacterial coinfection and guiding antibiotic use among children with enterovirus infection
}

\author{
Rui-Mu Zhang ${ }^{1} \cdot{\text { Kun } \operatorname{Tan}^{1} \cdot \text { Shu Fu }}^{1} \cdot$ Ji-Kui Deng ${ }^{1}$ (D)
}

Received: 8 October 2021 / Accepted: 13 December 2021 / Published online: 21 January 2022

(c) The Author(s) 2022

Procalcitonin (PCT), C-reactive protein (CRP), and white blood cell (WBC) have been used as markers of bacterial infection in children for decades. Previous studies have suggested PCT, CRP, WBC, and percentage of neutrophils $(\% \mathrm{~N})$ may be useful in detecting bacterial infection in children [1-4]. However, elevated levels of these biomarkers have also been noted in children with enterovirus infection [5-7]. In a study involving 5692 hospitalized children with herpangina or hand, foot, and mouth disease (HFMD) in two periods of years, the medians of CRP were 50.1 and $42.5 \mathrm{mg} / \mathrm{L}$, respectively; and the medians of WBC were 14.1 and $15.3 \times 10^{9} / \mathrm{L}$, respectively [5]. These biomarkers were sometimes considered as evidence of bacterial coinfection in children with enterovirus infection, which resulted in a high antibiotic prescribing rate. For children hospitalized for HFMD, the antibiotic prescribing rates ranged from 7.4\% to $100 \%$ in previous studies $[5,8,9]$. However, the value of these biomarkers in detecting bacterial coinfection among children with enterovirus infection is unclear.

We conducted a retrospective study in Shenzhen Children's Hospital, a 1300-bed tertiary care facility in Shenzhen, China. The study population consisted of all children hospitalized for herpangina or HFMD between January 2015 and December 2020. Enterovirus infection was defined as the presence of a positive polymerase chain reaction (PCR) test for enterovirus with an oropharyngeal swab or stool specimens. Single enterovirus infection was defined as the presence of enterovirus infection which could fully explain all the symptoms of the patient. Enterovirus infection severity was classified as mild or severe based on the Chinese guideline for the diagnosis and treatment of HFMD (2018 edition) [10]. Definitions of bacterial coinfection diseases

$\triangle$ Ji-Kui Deng

szsetyydeng@sina.com

1 Department of Infectious Diseases, Shenzhen Children's Hospital, Shenzhen 518038, China are summarized in Table 1. Cases were defined as patients with enteroviral and bacterial coinfection disease. Two controls with a single enterovirus infection were matched to each case by age (days) and sex. For cases who could not be matched by exactly the same age, they would be matched with controls of the most similar age.

Patients with any of the following factors were excluded: negative or absence of PCR test for enterovirus; absence of both the CRP and PCT tests; comorbidity other than bacterial coinfection; liver dysfunction (prothrombin time $>18$ seconds and serum bilirubin $\geq 20 \mu \mathrm{mol} / \mathrm{L}$ ) [12]; immunocompromised state or immunodeficiency; underlying chronic disease (autoimmune disease, thyroid disease, malnutrition, congenital heart disease, and chronic lung disease).

The clinical variables were measured every day during hospitalization. Blood samples were collected during hospitalization as needed to guide management decisions. Categorical variables were presented as number and percentage. Continuous variables were presented as mean \pm standard deviation (SD) if they were normally distributed or median (25-75\% interquartile range) if they had a skewed distribution. Chi-square test was used for categorical variables. The Student $t$ test or Mann-Whitney test was used for continuous variables, as appropriate. Binary logistic regression analysis was also performed to control confounding effects. Data analysis was performed by SPSS 26.0 software. All $P$-values were two-tailed, and $P<0.05$ was considered to indicate statistical significance.

We identified 45 cases and 90 controls (Fig. 1, Table 2). $\mathrm{CBC}$ and CRP tests were performed in all the included children. PCT test was performed in 37 cases and 83 controls. The medians of test timing (days after fever onset) for PCT, CRP, WBC, and N\% were, respectively, 4, 4, 3, 3 in cases and 3, 2, 2, 2 in controls. The maximal levels of inflammatory biomarkers in cases were as follows: PCT, $6.78 \mathrm{ng} / \mathrm{mL}$; CRP, $135.1 \mathrm{mg} / \mathrm{L}$; WBC, $32.53 \times 109 / \mathrm{L}$; and $\% \mathrm{~N}, 88.4 \%$. 
Table 1 Definitions of bacterial coinfection diseases in children with enterovirus infection

\begin{tabular}{ll}
\hline Bacterial coinfection diseases & Definitions \\
\hline Sepsis & Expert consensus for the diagnosis and management of septic shock (infectious shock) in children [11] \\
Bacterial pneumonia & Radiographic diagnosis of pneumonia + positive BALF/blood culture for bacteria \\
Bacterial enteritis & Diarrhea + positive culture/PCR test for bacteria from stool \\
Urinary tract infection & Fever/urinary symptoms + pyuria/positive urine culture for bacteria \\
Purulent tonsillitis & Tonsillar exudate + neutrophilia/positive RADT for GAS/positive throat culture for bacteria \\
Staphylococcal scalded skin syndrome & Classic cutaneous findings of SSSS + recovery after antibiotic treatment/positive culture for Staphylo- \\
& coccus aureus \\
Skin and soft tissue infections & Erythema, swelling, heat, and pain + recovery after antibiotic treatment/positive culture for bacteria \\
\hline
\end{tabular}

$B A L F$ bronchoalveolar lavage fluid; PCR polymerase chain reaction; RADT, rapid antigen detection test; GAS, group A Streptococcus; SSSS staphylococcal scalded skin syndrome

Fig. 1 Flow diagram for study design and data collection. HFMD hand, foot, and mouth disease, SSSS staphylococcal scalded skin syndrome

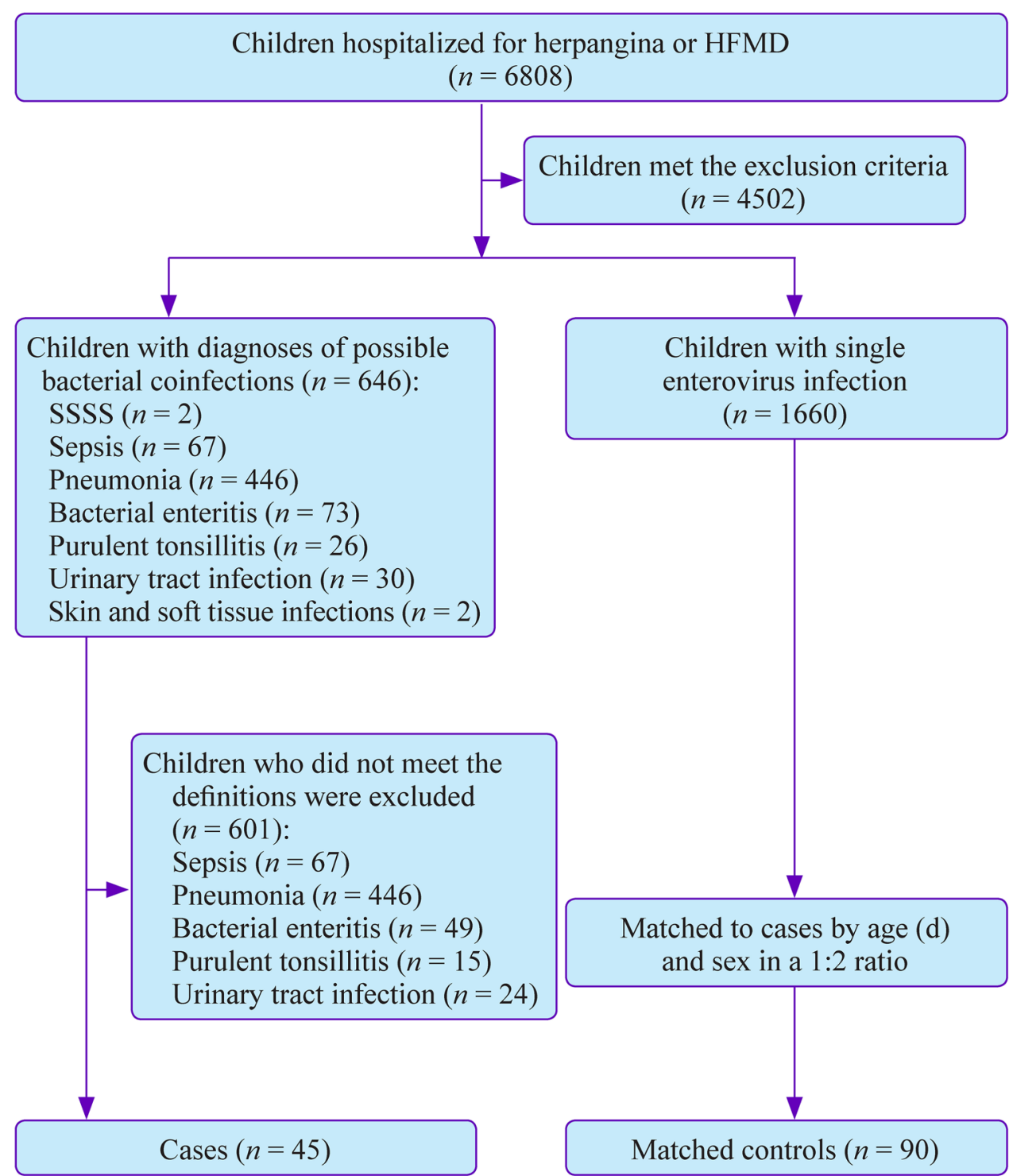


Table 2 Characteristics of hospitalized children with enteroviral and bacterial coinfection (Cases) and children with single enterovirus infection (Controls)

\begin{tabular}{|c|c|c|c|}
\hline Characteristics & Cases $(n=45)$ & Controls $(n=90)$ & $P$ value \\
\hline \multicolumn{4}{|l|}{ Demographics } \\
\hline Male, $n(\%)$ & $34(76)$ & $68(76)$ & - \\
\hline Female, $n(\%)$ & $11(24))$ & $22(24)$ & - \\
\hline Age, d & $537(393-732)$ & $536(394-729)$ & 0.966 \\
\hline \multicolumn{4}{|l|}{ Clinical features } \\
\hline Herpangina, $n(\%)$ & $11(24)$ & $14(16)$ & 0.210 \\
\hline Severe enterovirus infection, $n(\%)$ & $23(51)$ & $39(43)$ & 0.393 \\
\hline Duration of fever, $\mathrm{d}$ & $4(3-7)$ & $3(2-4)$ & - \\
\hline Antibiotic treatment, $n(\%)$ & $43(96)$ & $49(54)$ & - \\
\hline \multicolumn{4}{|l|}{ Coinfection diseases, $n$} \\
\hline SSSS & 2 & 0 & - \\
\hline Skin and soft tissue infection & 2 & 0 & - \\
\hline Urinary tract infection & 6 & 0 & - \\
\hline Purulent tonsillitis & 11 & 0 & - \\
\hline Bacterial enteritis & 24 & 0 & - \\
\hline \multicolumn{4}{|l|}{ Biomarkers } \\
\hline $\mathrm{PCT}, \mathrm{ng} / \mathrm{mL}^{\mathrm{a}}$ & $0.21(0.08-0.64)$ & $0.10(0.05-0.24)$ & 0.012 \\
\hline $\mathrm{CRP}, \mathrm{mg} / \mathrm{L}$ & $24.90(11.35-54.20)$ & $24.10(9.43-47.78)$ & 0.704 \\
\hline WBC count, $\times 10^{9} / \mathrm{L}$ & $15.01(11.18-16.92)$ & $15.64(13.25-20.73)$ & 0.140 \\
\hline$\% \mathrm{~N}, \%$ & $64(51-74)$ & $68(59-75)$ & 0.317 \\
\hline
\end{tabular}

Numbers are shown as median (25-75\% interquartile range) unless otherwise indicated

SSSS staphylococcal scalded skin syndrome, $P C T$ procalcitonin, $C R P$ C-reactive protein, $W B C$ white blood cell, $\% N$ percentage of neutrophils

${ }^{\text {aPCT }}$ test was performed in 37 cases and 83 controls
The maximal levels of inflammatory biomarkers in controls were as follows: PCT, $6.91 \mathrm{ng} / \mathrm{mL}$; CRP, $120 \mathrm{mg} / \mathrm{L}$; WBC, $42.73 \times 109 / \mathrm{L}$; and $\% \mathrm{~N}, 88.3 \%$. One case and three controls were infected by enterovirus 71 (EV71); one case and one control were infected by coxsackie A16 (CA16); and the remaining patients were infected by non-EV71 and nonCA16 enteroviruses. Of the 45 cases, 18 with bacterial enteritis had positive stool cultures for nontyphoidal Salmonella; one case with bacterial enteritis had positive blood and stool cultures for Salmonella typhi; five cases with urinary tract infection had positive urine cultures for bacteria; and the remaining cases had no positive culture results. No multiple bacterial infections were found in all cases. Most of the 45 cases received antibiotic treatment except for two cases with mild salmonella enteritis. None of the children were admitted to the intensive care unit and all of them were discharged with alleviation of symptoms.

Mann-Whitney test indicated that PCT level [0.21 $(0.08-0.64]$ vs. $0.10(0.05-0.240 \mathrm{mg} / \mathrm{L}, P=0.012)]$ was significantly higher in the cases than in the controls. In the
Table 3 Multivariate analysis of biomarkers in hospitalized children with enteroviral and bacterial coinfection (cases) and children with single enterovirus infection (Controls)

\begin{tabular}{lllll}
\hline Variables & Cases $(n=45)$ & Controls $(n=90)$ & $P$ value & Odds ratio (95\% CI) \\
\hline PCT, ng/mL ${ }^{\mathrm{a}}$ & $0.21(0.08-0.64)$ & $0.10(0.05-0.24)$ & 0.147 & $1.346(0.901-2.011)$ \\
$\mathrm{CRP}, \mathrm{mg} / \mathrm{L}$ & $24.90(11.35-54.20)$ & $24.10(9.43-47.78)$ & 0.417 & $1.006(0.991-1.021)$ \\
$\mathrm{WBC}$ count, $\times 10^{9} / \mathrm{L}$ & $15.01(11.18-16.92)$ & $15.64(13.25-20.73)$ & 0.140 & $0.945(0.877-1.019)$ \\
$\% \mathrm{~N}, \%$ & $64(51-74)$ & $68(59-75)$ & 0.617 & $0.992(0.961-1.024)$ \\
Herpangina, $n(\%)$ & $11(24)$ & $14(16)$ & 0.150 & $2.132(0.761-5.975)$ \\
$\quad$ Severe enterovirus & $23(51)$ & $39(43)$ & 0.371 & $1.478(0.628-3.480)$ \\
$\quad$ infection, $n(\%)$ & & & &
\end{tabular}

Numbers are shown as median (25-75\% interquartile range) unless otherwise indicated

$C I$ Confidence interval; $P C T$ procalcitonin; $C R P$ C-reactive protein; $W B C$ white blood cell; $\% N$ percentage of neutrophils

${ }^{\text {a }} \mathrm{PCT}$ test was performed in 37 cases and 83 controls 
further binary logistic regression analysis, there were no significant differences in PCT, CRP, WBC, or $\% \mathrm{~N}$ between the cases and the controls (Table 3 ).

Of the 90 controls, 49 (54\%) received antibiotic treatment. Mann-Whitney test and chi-square test indicated that there were no significant differences in duration of fever [2.00 (2.00-3.00)] vs. $3.00(2.00-4.00)$ days, $P=0.075]$ and length of hospitalization [ $4.00(3.00-5.00)$ vs. 4.00 (3.00-4.00) days, $P=0.260$ ] between controls with and without antibiotic treatment.

In this study, we identified 45 children with enteroviral and bacterial coinfection and 90 matched children with single enterovirus infection. Univariate and multivariate analysis suggested that there were no significant differences in the biomarkers between the two groups, revealing the poor utility of these biomarkers in identifying bacterial coinfection among children with enterovirus infection. Similarly, $\mathrm{CRP}, \mathrm{WBC}$, and $\% \mathrm{~N}$ also showed limited diagnostic value in fracture-related infections in adults [13]. This indicates the application of inflammatory biomarkers may not be suitable under certain circumstances, and the results should be taken with caution. We also found that antibiotics did not significantly shorten the duration of fever or length of hospitalization in children with a single enterovirus infection. Clinicians should not prescribe antibiotics only based on elevated levels of inflammatory biomarkers.

Author contributions All authors were involved in the critical revision of the manuscript. ZRM and DJK contributed to the study conception and design. TK and FS enrolled patients and collected clinical data. ZRM analyzed clinical data and drafted the manuscript. DJK had contributions to the revision of the manuscript in discussion, data re-evaluation and presentation, and manuscript edition. All authors approved the final version of the manuscript, including the authorship list.

Funding This work was supported by Shenzhen Fund for Guangdong Provincial High-level Clinical Key Specialties [SZGSP012] and Project of the Expert Committee on Clinical Application and Drug Resistance Evaluation of Antimicrobial Drugs of the National Health Commission (KJYWZWH-OT-02-2021-01).

Data availability The datasets generated during and/or analyzed during the current study are available from the corresponding author on reasonable request.

\section{Declarations}

Conflict of interest The authors have no conflict of interest to declare. No financial or non-financial benefits have been received or will be received from any party related directly or indirectly to the subject of this article.

Ethical approval This study was approved by the ethics committee of Shenzhen Children's Hospital with judgment's reference number 201907903.
Open Access This article is licensed under a Creative Commons Attribution 4.0 International License, which permits use, sharing, adaptation, distribution and reproduction in any medium or format, as long as you give appropriate credit to the original author(s) and the source, provide a link to the Creative Commons licence, and indicate if changes were made. The images or other third party material in this article are included in the article's Creative Commons licence, unless indicated otherwise in a credit line to the material. If material is not included in the article's Creative Commons licence and your intended use is not permitted by statutory regulation or exceeds the permitted use, you will need to obtain permission directly from the copyright holder. To view a copy of this licence, visit http://creativecommons.org/licenses/by/4.0/.

\section{References}

1. van Rossum A, Wulkan RW, Oudesluys-Murphy AM. Procalcitonin as an early marker of infection in neonates and children. Lancet Infect Dis. 2004;4:620-30.

2. Trippella G, Galli L, De Martino M, Lisi C, Chiappini E. Procalcitonin performance in detecting serious and invasive bacterial infections in children with fever without apparent source: a systematic review and meta-analysis. Expert Rev Anti Infect Ther. 2017;15:1041-57.

3. Honda T, Uehara T, Matsumoto G, Arai S, Sugano M. Neutrophil left shift and white blood cell count as markers of bacterial infection. Clin Chim Acta. 2016;457:46-53.

4. Yo CM, Hsieh PB, Lee SM, Wu JM, Chang SM, Tasi KMM, et al. Comparison of the test characteristics of procalcitonin to c-reactive protein and leukocytosis for the detection of serious bacterial infections in children presenting with fever without source: a systematic review and meta-analysis. Ann Emerg Med. 2012;60:591-600.

5. Kuo K, Yeh Y, Huang Y, Chen I, Lee C. Understanding physician antibiotic prescribing behavior for children with enterovirus infection. PLoS One. 2018;13:e202316.

6. Duan F, Deng M, Lin Y, Hou X, Gu Y. Significance of procalcitonin and other inflammatory markers in pediatric patients with HFMD. Int J Lab Med. 2015;36:446-8.

7. Zhou Y, Cai Z. Application of procalcitonin detection in children with hand, foot, and mouth disease complicated with bacterial infection. Heilongjiang Med J. 2017;41:1111-3 (in Chinese).

8. Xu Q, Gao L, Wei H, Hu S, Zhang F, Deng Z, et al. Risk factors of death cases of hand, foot, and mouth disease in Harian province. Chin J Prev Med. 2011;45:904-8 (in Chinese).

9. Xiong H, Pan F, Nie M, He M. A clinical retrospective analysis about application of antibiotics in treatment of 274 cases of hand, foot, and mouth disease. CN Modern Med. 2011;18:32-3 (in Chinese).

10. Li X, Ni X, Qian S, Wang Q, Jiang R, Xu W, et al. Chinese guidelines for the diagnosis and treatment of hand, foot and mouth disease (2018 edition). World J Pediatr. 2018;14:437-47.

11. Chinese Medical Association, Chinese Medical Doctor Association. Expert consensus for the diagnosis and management of septic shock (infectious shock) in children (2015). Chin J Pediatr. 2015;53:576-80 (in Chinese).

12. Mackenzie I, Woodhouse J. C-reactive protein concentrations during bacteraemia: a comparison between patients with and without liver dysfunction. Intens Care Med. 2006;32:1344-51.

13. Sigmund IK, Dudareva M, Watts D, Morgenstern M, Athanasou NA, Mcnally MA. Limited diagnostic value of serum inflammatory biomarkers in the diagnosis of fracture-related infections. Bone Joint J. 2020;102-B:904-11.

Publisher's Note Springer Nature remains neutral with regard to jurisdictional claims in published maps and institutional affiliations. 